\title{
Yersinia ruckeri Suşlarında Çevreyi Algılama Sistemi ve Yönetimindeki Virülens Faktörlerinin
} Araştırılması

\author{
Nurdan FİLiK* ${ }^{*}$, Ayşegül KUBíLAY \\ Isparta Uygulamalı Bilimler Üniversitesi, Eğirdir Su Ürünleri Fakültesi, Isparta, Türkiye. \\ *Sorumlu Yazar: nurdansal@hotmail.com
}

Geliş 09 Mart 2019; Kabul 11 Temmuz 2019; Basım 15 Eylül 2019.

Alıntılama: Filik, N., \& Kubilay, A. (2019). Yersinia ruckeri suşlarında çevreyi algılama sistemi ve yönetimindeki virülens faktörlerinin araştırılması. Acta Aquatica Turcica, 15(3), 391-403. https://doi.org/10.22392/actaquatr.537802

\section{Özet}

Gram-negatif balık patojenleri çevreyi algılama (QS) yönetimindeki AHL ( $N$-Acyl homoserine lactones) molekülleriyle virülens faktörleri üzerinde etkili olarak balıklarda enfeksiyon oluşturur. Araştırmada bakteriyel balık patojeni klinik $Y$. ruckeri (12 suş) kullanılmıştır. Acyl yan zincirinde 4-8 karbona sahip $N$-butanoyl-L-homoserin lakton (BHL) ve Acyl yan zincirinde 6-12 karbona sahip $N$-(3-okzododekanoyl)-L-homoserin lakton (OdDHL) sinyal moleküllerinin üretimi, Chromobacterium violaceum CV026 ve Agrobacterium tumafeciens NT1 mikrobiyolojik monitör sistemleri (biyosensör suşlarıyla) araclığıyla araștırılmıștır. Pozitif kontrol olarak Pseudomonas aeruginosa PAO1 suşu kullanılmıștır. Testlerle Yersinia ruckeri suşlarının, $C$. violaceum CV026 aracılığıyla BHL molekülünü, A. tumafeciens NT1 aracılığıyla OdDHL molekülünü ürettiği tespit edilmiştir. Elastaz spektrofotometreyle, ramnolipid 0,2 g CTAB (Cetiltrimetilamonyumbromid), $5 \mathrm{mg} / \mathrm{l}$ metilen mavisi ve M9-glutamat minimal medium agarla araştırılmıştır. Hemoliz \%5 kanlı agarda, proteaz \%2 yağsız süt tozlu agarda, amilaz \%2 nişastalı agarda bakterilerin inokülasyonuyla araştırılmıştır. Sonuçta $Y$. ruckeri ürettikleri sinyal molekülleri aracılığıyla iletişim kurmakta ve istedikleriçoğunluğa ulaştıkları anda balık için kritik gen ekspresyonlarını tetikleyerek virülens faktörlerini üretmektedir. Ayrıca busuşlarının azda olsa elastazı ürettiği belirlenirken, ramnolipid, proteaz, amilaz ve hemoliz aktiviteleri gibi virülens faktörlerini üretmediği belirlenmiştir. $Y$. ruckeri'nin çevreyi algılama molekülleri BHL ve OdDHL'yi kullandığı belirlenmiştir. P.aeruginosa insan patojenine özgü virülens faktörlerielastaz ve ramnolipidin $Y$. ruckeri'ye uyarlanarak araştırılmasının sonucunda elastazın bulunması $Y$. ruckeri'nin patojenitesi açısından değerlidir.

Anahtar kelimeler: Yersinia ruckeri, çevreyi Algılama Sistemi, AHL molekülleri, virülens faktörleri, elastaz

\section{Investigation of Virulence Factors in Management and Quorum Sensing System in Yersinia ruckeri Strains}

\begin{abstract}
Gram-negative fish pathogens cause infection in fish by detecting quorum sensing managing factors (QS) with AHL ( $N$ Acyl homoserine lactones) molecules on virulence factors. Bacterial fish pathogen clinical Y. ruckeri (12 strains) were used in this study. Researched production of signaling molecules of $N$-butanoyl-L-homoserine lactone (BHL) own 4-8 carbons in the Acyl side chain and $\mathrm{N}$-(3-octododecanoyl)-L-homoserine lactone (OdDHL) own 6-12 carbons in the Acyl side chain, via Chromobacterium violaceum CV026 and Agrobacterium tumafeciens NT1 are microbiological monitoring systems (upon biosensor strains). Pseudomonas aeruginosa PAO1 strain was used as positive control. Yersinia ruckeri strains were found to produce BHL molecule via $C$. violaceum CV026 and OdDHL moleculevia A. tumafeciens NT1 upon testes. Elastase upon spectrophotometer, rhamnolipid $0.2 \mathrm{~g} \mathrm{CTAB}$ (Cethyltrimethylammonumbromid), $5 \mathrm{mg} / \mathrm{l}$ methylene blue and M9-glutamate minimal medium agar were researched. hemolysinin $\% 5$ blood agar, protease in $\% 2$ skimmed milk agar, amylase in $\% 2$ starch agar uponinoculation of bacteria were researched. As a result, Y. Ruckeri communicates via the signal molecules they produce and when reach the majority want, produce virulence factors by triggering critical gene expression for fish. In addition, it has been determined that these strains produce elastase at least, whereas it does not produce virulence factors such as rhamnolipid, protease, amylase and hemolysis activities. Y. ruckeri was determined to use quorum sensing molecules BHL and OdDHL. $P$. aeruginosa human pathogen specific of virulence factors elastase and rhamnolipid adaptation toY. ruckerias a result of research presence of elastase is valuable in terms of pathogenesis of Y. ruckeri.
\end{abstract}




\section{GíRiș}

Enterobacteriaceae familyası üyesi olan Yersinia ruckeri Gram-negatif, basil, 1-0,75 $\mu \mathrm{m}$ çapında ve 1,0-3,0 $\mu \mathrm{m}$ uzunluğunda (Tkachenko vd., 2019), sporsuz, kapsülsüz, flagella her zaman mevcut olmadığından değişken motilite gösteren bir bakteridir (Davies ve Frerichs, 1989; Ohtani vd., 2019). $Y$. ruckerisalmonid balıklarda subakut, akut veya kronik septisemi ile seyreden bulaşıcı bir hastalık etkeni olarak ilk kez 1955'de bildirilmiştir. Kültürü yapılan gökkuşağı alabalıklarında (Oncorhynchus mykiss) ve Atlantik salmonlarda (Salmo salar) yüksek mortaliteye ve önemli ekonomik kayıplara neden olan firsatçı bir patojen olduğu rapor edilmiştir (Austin ve Austin, 1987; Petrie vd., 1996; Ormsby vd., 2019). Hastalığa, ilk görüldüğü vadinin ismi olan "Hagerman Redmouth" adı verilmişse de 1975'te Amerikan Balıkçılar Birliği'nin Balık Sağlığı Bölümü tarafından hastalığın adı "Enteric Redmouth" (ERM) veya Yersiniozis olarak değiştirilmiştir (Austin ve Austin, 1987; Furones vd., 1993; Austin ve Austin, 1999; Balta vd., 2016).Yersiniozis ağız çevresi, operkulum, yüzgeç tabanları ve anüs etrafında hemorajiler (Fuhrmann,1983) karaciğer, böbrek, bağırsak,dalak gibi iç organlarda noktasal kanamalarla karakterize olan (Rodgers, 1992) bakteriyel bir enfeksiyondur (Austin vd.,1982; Secades ve Guijarro, 1999; Rigos ve Stevenson, 2001).

Erwin F. Smith (1905)'e göre çok sayıdaki bakteri bir kaç bakteriden daha güçlü olduğu, ancak bu bir kaç bakterinin de birlik olarak engelleri aşabileceği ve enfeksiyon sürecini daha rahat başlatabileceğini bildirmiştir. İşte bu sözlerden yıllar sonra, yapılan çalışmalar ile tek hücreli bakterilerin birbirileri ile iletişim kurabildiği ve değişen bir ortama yanıt verebildikleri gösterilmiştir (Baskın, 2005; Boşgelmez-Tınaz, 2003). Bakterilerin değișen ortam koșullarına uyumlarını kolaylaștırmak için karmașık hücreler arası iletișim sistemleri kullanan topluluklar olduğunu "yalnız yaşayan" ve "yalnız ölen" izole varlıklar olmadıkları araştırmalarla desteklenmektedir (Swift vd., 1994).

Bakteriler birbirlerinianlamak amacıyla Çevreyi Algılama (Quorum Sensing, QS) denilen sistemi kullanırlar. Bakterilerin her bir türü birbirleriyle iletisim kurmak için birden fazla sayıda veya birden fazla çeşitte sinyal molekülü kullanırlar. Bu sinyal molekülleri, bakteriyel populasyonlara kendi hücre yoğunluklarını algılama imkânı sağlar. Bakterilerin bu şekilde kendi populasyon yoğunluklarını algılayabilme yeteneklerine "Çevreyi Algılama" denir (Fuqua vd., 1994).Bu sistem sinyal molekülerinin kullanımı ve algılanmasıyla gerçekleşir.Hatta bu sinyal moleküler ile bakteriler kendi sayılarını bile algılayabilirler.Bakterilerin kullandıkları sinyallerin yapay sinir ağları ile olan benzerlikler göze çarpmaktadır. Bakterilerin bir sinir ağı özelliklerinin birçoğunu barındırdı̆̆ bulgusundan hareketle bakteriler için düşük düzeyde bir zekâ yapısı söz konusu olabilir (Hellingwerf, 2005). Çevreyi algılama ilebiyofilm oluşumu, beslenme, üreme, spor oluşumu, antibiyotiklere karşı direnç gibi olaylar sinyal moleküleri aracılığıyla gerçekleşir (Throup vd., 1994).OS; bu söz konusu sinyal molekülerinin salınımını gerçekleştiren ve bakteri popülasyonunu koordine eden düzenleyici bir network sistemidir (Sarabhai vd., 2016; Asif vd.,2019). QS sisteminin en etkili özelliği bakterilerin popülasyon yoğunluğunu anlamas1 ve virülens faktörlerini düzenlemesidir (Watve vd., 2019).Mikrobiyologlarçevreyi algılama ile ilgili yapılan araştırmalar sonucunda mikroorganizmalar arasındaki sinyal moleküleri bozarak laboratuvar ortamında mikroorganizmaların sayılarını kontrol altında tutmayı başarmışlardır (Throup vd., 1994). Bakteriler arasındaki bu sinyal molekülerini kullanan mikrobiyologlar bakterileri öldürmek yerine aralarındaki bu sinyal molekülerini durdurmuşlardır(Throup vd., 1994).

Salgılanan moleküler ve kullanılan algılama düzeneğine göre üç tip çevreyi algılama mekanizması vardır: Gram-negatif bakterilerde LuxI homologları denilen bazı enzimler türe özgü AHL moleküllerini katalizler. Bu AHL'lar LuxR tipi transkripsiyonel düzenleyiciler tarafindan algılanır. Gram-pozitif bakterilerde ise sinyal iletimi için oligopeptitlere bağlı olarak iki bileşenli fosforlama zinciri kullanılır. Üçüncüve son mekanizma "Hibrit sistem"dir. V. harveyi modelide denir. Burada hem oligopeptidleri görülür hemde LuxI/LuxR tipi proteinler hücre içinde sinyal yolunda görev alır. LuxLM tarafından; AI-1 ve LuxS tarafından AI-2 sinyal molekülleri olmak üzere iki tip sinyal üretilir. AI-1 molekülü tür içi sinyalleşmeyi sağlarken AI-2 (LuxS) türler arası sinyalleşme de görev alır. Türler arası sinyalleşmeye "cross-talk"da denir(Raffa vd., 2005; Sequences, 2008).

$Y$. ruckeri' de çevreyi algilama sisteminin $C$. violaceum CV026 biyosensör suşuyla varllğg 1 saptanmıştır. Y. ruckeri'nin çevreyi algılama sistemi; pUC18 plazmit taşıyıcısı olarak kurgulanmış, gen kütüphanesinden klonlanmış ve yruR/yruI olarakadlandırılmıştır (Temprano vd., 2001). Y. 
ruckeri'nin N-3-oktanoil homoserin lakton (OHL) sinyal molekülünü üretmektedir (Bruhn vd., 2005).Virülens faktörlerinden yüzme hareketliliği ve biyofilm oluşumu çevreyi algılamatarafindan düzenlenirken, kazeinaz, fosfolipaz ve hemoliz üretiminin 3oxo-C8-HSL sinyal molekülünün salınımı sonrası düzenlenmediği görülmüştür (Delshad vd., 2018).

İnsan kaynakl1 Chromobacterium violaceum CV026, Agrobacterium tumafeciens NT1 ve Pseudomonas aeruginosa'daçevreyi algılama sistemi araştırılıdı̆̆ında $C$. violaceummor pigment violacein özelliğini üretir. Daha önce yazarlar bir violacein-negatif, pigment üretiminin süpernatant ile inkübasyon ile iade edilebildiği $C$. violaceum CV026'nın mini-Tn5 mutant'1 olarak tanımlamışlardır (McClean vd., 1997). Yine bu bakterinin sinyal molekülü üretemeyen mutantı, diğer bakterilerin açil homoserin lakton molekülü üretimlerini test etmek için kullanılmaktadır (Sharma vd., 2003). A. tumefaciens mutant suşu ortamda AHL molekülü varlığında orijinal rengi olan yeşil pigment bırakır. Ti plazmid üzerinde bulunan Tra genleri $L u x I$ ve $\operatorname{LuxR}$ homoloğu olan TraI ve TraR proteinleri ve sinyal molekülü olan $N$-3(okzokitonol)-L-homoserin lakton aracılığıyla aktive edilirler (BoşgelmezTinaz, 2003). P. aeruginosa'da, AHL sinyal moleküllerine dayanan, kendi popülasyon yoğunluklarını algılamalarını sağlayan ve çevreyi algılama sistemi olarak adlandırılan mekanizmayı kullanırlar (Kleerebezem vd., 1997; Ulusoy, 2007). Bu iletişim sisteminin temeli iki protein molekülüne bağlıdır. Bunlardan birisi LuxI ailesine mensup AHL sentez ve diğeri de LuxR ailesine ait AHL reseptör proteinidir. Hücre yoğunluğundaki artışa paralel olarak AHL sinyal moleküllerinde de artış gözlemlenir. Hücre yoğunluğunun artmasıyla AHL sinyal molekülleri sayıca artar ve sinır değere ulaştığı zaman AHL LuxR-tip reseptör proteine bağlanarak hedef genlerin uyarılmasını veya baskılanmasını sağlar(Kleerebezem vd., 1997).Balık patojeni Vibrio anguillarum çevreyi algılama sistemi sinyal moleküllerinden 3-Okzo-C10-HSL molekülünü salgılayarak regülatör proteinleri VanI/VanR sayesinde fenotipik etkilerini gösterir (Ulusoy, 2007). LuxS; çevreyi algılama sisteminde proteaz üretimi ve EPS, biyofilm tabakası, flegella/motilite (hareket) gibi fenotipikle ilişkisi olan birçok düzenleme kadar Vibrio alginolyticus 'un virülensinde de önemli bir rol oynamaktadır (Ye vd., 2008). Pseudomonas fluorescens kontrolü çevreyi algılama sisteminde olan 3-Oxo-C10-HSL sinyal molekülünün dışarı bırakılmasından sonra Mupirosini fenotipik etki olarak gösterir (Williams, 2007). Aeromonas hydrophila'da LuxRI homolog AhyRI ve Aeromonas salmonicida'da LuxRI homolog AsaRI'nin varlığıyla AHL moleküllerinden ( $N$-butanoyl-L-homoserin lakton [BHL]) her iki bakteride de bulunmaktadır. Ayrıca, A. hydrophila ve A. salmonicida'da serine proteaza üretimi çevreyi algılama için bir kanıttır (Swift vd., 1997).

Bakteriler çevreyi algılama sistemiyle virülens faktörlerini yönetir ve etkinleştirir. Ramnolipid hemolitik etkisi olan hemolizindir, mukosiliyer taşınımı ve silya fonksiyonlarını inhibe eder. $P$. aeruginosa'nın elastolitik etkisinden LasA proteaz ve LasB elastaz sorumludur (Salyers ve Whitt, 1994). Proteaz roteinlerin parçalanmasından sorumlu enzim grubudur (Turus, 2011). Nişasta çözünmeyen granüller formunda olup (Polaina ve MacCabe, 2007) mikroorganizmalarnişastayı parçalayan enzimler üretmektedir (Yamamoto vd., 2000; Gawande ve Patkar, 2001). Bakteriler sahip kandakihemoglobini farklı derecelerde hemoliz etme yani parçalama yeteneğine sahiptirler.Sonuç olarak ekzoenzim serin proteaz, ekzotoksin $\alpha$-hemolizin ve hücre dışı protein olan sidereforgibi virülens faktörleri yüksek bakteri yoğunluğuna bağlı olarak çevreyi algılamasisteminin kontrolündeki genlerin ekspresyonuyla ortaya çıkar (Jangid vd., 2007). A. hydrophila ve Aeromonas salmonicida $\mathrm{N}$ Açil homoserin lakton molekülleri üretirler veya LuxRI'ın homologlarını içerirler. Bu patojenler LuxRI'ın homologları olan AhyRI ve AsaRI'1 exprese ederek BHL ve HHL sinyal moleküllerinin sentezini düzenlerler.Vibrio anguillarum'da LuxRI homoloğu olan VanI $N$-(3-oxo-Dekanoyl)-L-HSL (ODHL) molekülünün sentezini katalizler (Sharma vd., 2003). Çevreyi algılama sistemi proteaz, EPS, biyofilm, motilite $V$. alginolyticus'un virülensinde etkilidir (Ye vd., 2008). P. fluorescens çevreyi algılama kontrolündeki 3-Oxo-C10-HSL sinyal molekülünün başka $P$. fluorescens' in algılamasından sonra Mupirosini etki olarak gösterir (Williams, 2007). A. hydrophila ve A. salmonicida BHL molekülüyle serine proteaz üretir (Swift vd., 1997). Elastaz ve ekzotoksin A gibi, üretimi çevreyi algılama sistemi tarafından kontroledilen virülens faktörleri bazı suşlarda tanımlanmıştır (Hamood vd., 1996; Rumbaugh vd., 1999; Zhu vd., 2004).

$\mathrm{Bu}$ araştırmada $Y$. ruckeri suşlarının patojenitesinin yetkinliği açısından; fenotipik olarak çevreyi algılama sistemini kullanıp kullanmadığ yapma gücünden sorumlu olduğu virülens faktörleri elastaz, ramnolipid, proteaz, amilaz, hemoliz üretiminin tespiti amaçlanmıştır. 


\section{MATERYAL ve YÖNTEM}

\section{Y. ruckeri Suşlar ve Gelişme Koşulları}

Araştırmada ISUBÜ Eğirdir Su Ürünleri Fakültesi Balık Hastalıkları Laboratuvarı'ndan temin edilen, hasta balıkların iç organlarından izole edilmiş ve moleküler düzeyde identifikasyonu yapılmış olanbalık patojeni $Y$. ruckeri'nin 12 suşu kullanılmıştır. Suşlar kullanılıncaya kadar McFarland 0,5'e göre standardize edilen miktarda- $80^{\circ} \mathrm{C}^{\prime}$ de ve $\% 20$ gliserin içerisinde muhafaza edilmiştir. Depolanan suşlar günlük kullanım için- $80^{\circ} \mathrm{C}^{\prime}$ den alınarak $-20^{\circ} \mathrm{C}^{\prime}$ de bekletildikten sonra TSA besiyerlerine ekilmiştir. Ekimleri yapılan suşlar $25^{\circ} \mathrm{C}^{\prime}$ de 24 saat süreyle inkübe edilmiştir. Daha sonra günlük kullanım amacıyla maximum 7 gün süreyle $+4^{\circ} \mathrm{C}$ 'de saklanmıştır. SDÜ Fen Edebiyat Fakültesi Biyoloji Bölümü'nden temin edilen pozitif kontrol olarak kullanılan $P$. aeruginosa PAO1 (1 suş) suşu, $\mathrm{LB}$ besiyerinde $30^{\circ} \mathrm{C}$ 'de üretilmiştir ve $-80^{\circ} \mathrm{C}$ ' de ve $\% 20$ gliserol içerisinde muhafaza edilmiştir. AHL sinyal moleküllerinin tespiti $C$. violaceum CV026 (1 suş) suşuve A. tumefaciens NT1 (1 suş) suşu kullanılarak yapılmıştır. Bu suşlar \%1,2 agar içeren katılaştırılmış ve A. tumefaciens NT1 suşu için gentamisin $(20 \mu \mathrm{g} / \mathrm{ml})$; C. violeceum suşu için kanamisin $(20 \mu \mathrm{g} / \mathrm{ml})$ LB (\%1 tripton, \%0,5 maya ekstraktı, $\% 0,5 \mathrm{NaCl}$ ) besiyerinde 24 saat süreyle $30^{\circ} \mathrm{C}$ 'de üretilmiştir. $\mathrm{Bu}$ stok kültürler farklı testler için kullanılmıştır (Ulusoy, 2007).

\section{Kimyasal maddeler}

Çalışmada; gliserol (Acar Chemicals), X-Gal (5-Bromo-4-kloro-3-indolil- $\beta$-Dgalaktopiranosid) (Sigma-Aldrich),gentamisin (Oxoid;10 $\mu$ g), etanol (Sigma-Aldrich), kanamisin (Sigma-Aldrich), lugol solüsyonu (Biorad), $\mathrm{Na}_{2} \mathrm{HPO}_{4}$ (Sigma-AldrichNIST SRM 2186II), $\mathrm{KH}_{2} \mathrm{PO}_{4}$ (Sigma-Aldrich NIST SRM 200B), $\mathrm{NaCl}$ (Merck), $\mathrm{NH}_{4} \mathrm{Cl}$ (Sigma-Aldrich A9434), $\mathrm{MgSO}_{4} \cdot 7 \mathrm{H}_{2} \mathrm{O}$ (Sigma-Aldrich), $\mathrm{CaCl}_{2} .2 \mathrm{H}_{2} \mathrm{O}$ (Sigma-Aldrich), glikoz (PubChem),glutamat (SAFC), metilen mavisi (Supelco), cetiltrimetilamonyumbromid (CTAB) (Sigma), tris (Merck), $\mathrm{CaCl}_{2}(\mathrm{Sigma})$, elastinkongo red (ECR) (Sigma) kullanılmıştır.

\section{Mikrobiyolojik monitör sistemleriyleAHL moleküllerinin tespiti}

Ulusoy (2007) tarafindan modifiye edilen McClean vd. (1997)'nin metodundan yararlanılmıştır. $Y$. ruckeri Tryptik Soy Agar (TSA)'da $25^{\circ} \mathrm{C}$ 'de 24 saat üretilmiştir. Y. ruckerisuşları ve C. violaceum CV026 biyosensör suşu aralarında $3 \mathrm{~mm}$ olacak şekilde karşılıklı ekilmiş ve $30^{\circ} \mathrm{C}$ ' de 24 saat inkübasyona bırakılmıştır. İnkübasyon sonucunda renk değişikliğine bakılmıştır. Mor renk görülmesi BHL'nun varlığını belirtmektedir. OdDHL molekülünün varlığı araştırmak için de aynı prosedür uygulanmıştır. Yeşil renk aranırkenpZLR4 plazmiti taşıyanA. tumefaciens NT1 suşu için tek fark olarak $20 \mu \mathrm{g}$ X-Gal ilaveliLuria Bertani Agar (LBA) kullanılmıştır. Sonuçlar pozitif kontrol $P$. aeruginosa PAO1 suşuyla karşılaştırılarak tespit için çapraz doğrulama testi yapılmıştır (Mohaddam vd., 2014).

\section{Elastaz testi}

Ohman vd. (1980)'nin belirttiği prensiple yapılmıştır. Y. ruckeri suşlarına Elastin Kongo Red (ECR) testi uygulanmıştır. Y. ruckeri suşları $25^{\circ} \mathrm{C}$ 'de 14 saat Luria Bertani Broth (LBB) besiyerinde üretilmiştir. Üretilen kültürlerin süpernatantlarından $100 \mu 1$ üzerine $900 \mu 1 \mathrm{ECR}$ tamponu $(100 \mathrm{mM}$ Tris, $1 \mathrm{mM} \mathrm{CaCl}_{2}$, pH 7,5, $20 \mathrm{mg}$ ECR) ilave edilmiş ve $25^{\circ} \mathrm{C}^{\prime}$ de 3 saat karıştırılarak hareket halinde inkübasyona bırakılmıştır. İnkübasyon sonucunda 12000 devirde 2 dk çözülmemiş olan ECR santrifüj edilerek uzaklaştırılmıştır. Süpernatantlar 96 çukurlu yuvarlak tabanlı plaklara $100 \mu$ l olarak çalışılmıştır. Plaklar OD'si 630 nm'de ELİSA okuyucusunda optik yoğunlukları ölçülmüsstür. Her bakteri için 7 sonucun OD değerlerinin ortalamaları alınmıştır. Test sırasında LBB negatif kontrol PAO1 suşu pozitif kontrol olarak kullanılmıştır (Ulusoy, 2007).

\section{Ramnolipid üretimi testi}

Siegmund ve Wagner (1991)'in prensibine göre yapılmış bir testdir. Ramnolipid üretimi testi; 0,2 g cetiltrimetilamonyumbromid (CTAB) ve $5 \mathrm{mg} / \mathrm{l}^{-1}$ metilen mavisi içeren $\mathrm{M} 9$-glutamat minimal medium agar petrileri kullanılmıştır. LBB besiyerinde $25^{\circ} \mathrm{C}$ 'de 24 saat $Y$. ruckeris uşları üretilmiştir. $\mathrm{Bu}$ suşların bir gecelik kültürlerinden 25'şer $\mu 1$ alınarak M9-glutamat minimal medium agar petrilerinin ortasına damlatılmıştır. Hazırlanan bu petriler $25^{\circ} \mathrm{C}$ de $24-48$ saat inkübasyona bırakılmıştır. 
İnkübasyon sonucunda bakteri kolonisi etrafindaki sarı-saydam zon ramnolipid aktivitesinin varlığını gösterir. Test sırasında LBB negatif PAO1 suşu pozitif kontrol olarak değerlendirilmiştir (Ulusoy, 2007; Onwosi ve Odibo, 2012).

\section{Proteaz testi}

Y. ruckeri suşlanı Tryptik Soy Broth (TSB) besiyerinde $25^{\circ} \mathrm{C}$ 'de 24 saat üretilmiştir. TSA petrilerinin ortasına yaklaşık $3 \mathrm{~mm}$ çaplı çukurlar açılmış ve her bir kültürden $\% 2$ yağsız süt tozu içeren bu çukurların içine $20 \mu \mathrm{l}$ ilave edilmiş ve $25^{\circ} \mathrm{C}$ 'de 24 saat inkübe edilmiştir. Bakteri kolonisi etrafında saydam zon oluşması proteolitik aktivitenin varlığını, zon oluşmaması yokluğunu göstermektedir (Arda, 1997; Swift vd., 1999; Dong vd., 2005; Ulusoy, 2007).

\section{Amilaz testi}

Y. ruckeri suşları ise TSB besiyerinde $25^{\circ} \mathrm{C}$ 'de 24 saat üretilmiştir. $\% 2$ nişasta ilaveli TSA besiyerine çizgi ekimi yapılmış ve $25^{\circ} \mathrm{C}$ 'de 24 saat inkübasyona bırakılmıştır. İnkübasyondan sonra koloniler üzerine lugol solüsyonu damlatılmış, pozitif reaksiyonlarınkoloni etrafında saydam alan oluşturması beklenmiştir. Negatif durumlarda ise besiyerinin mavi renkte görülmesi beklenmiştir. Koloni etrafında oluşan pembe-esmer bölge şüpheli reaksiyonu ifade etmektedir. Reaksiyon $5 \mathrm{dk}$ içinde okunmuştur (Arda, 1997; Swift vd., 1999). Amilaz testi her suş için üç defa tekrarlanmıştır.

\section{Hemoliz testi}

Y. ruckeri suşları ise TSB besiyerinde $25^{\circ} \mathrm{C}$ 'de 24 saat üretilmiştir.\%5 koyun kanı içeren TSA petrilerinin ortasına, $25 \mu \mathrm{l}$ ilave edilmiş ve $25^{\circ} \mathrm{C}$ 'de 24 saat inkübasyona bırakılmıştır. Suşların etrafında saydam zon oluşup oluşmamasına göresonuçlar değerlendirilmiştir (Swift vd., 1999). Hemoliz testi her suş için üç defa tekrarlanmıştır.

\section{ARAŞTIRMA BULGULARI}

Mikrobiyolojik monitör sistemleri (C. violaceum CV026 ve $A$. tumefaciens NT1),P. aeruginosa PAO1,Y. ruckeri'nin Koloni Yapıları

Orijinal suşta $C$. violaceum 12472 (Şekil 1) mor renk koloni ve C. violaceum CV026 (Şekil 2) mutant suşta ise pigmentsiz koloni oluşumu gözlenmiştir. OdDHL sinyal molekülünün üretimini gösteren A. tumefaciens NT1 mutant suşunun koloni yapısı (Şekil 3)'de, pozitif kontrol insan patojenin koloni yapısı $P$. aeruginosa PAO1 (Şekil 4)'de ve $Y$. ruckeri'nin koloni yapısı (Şekil 5) LBA üzerinde verilmiştir.

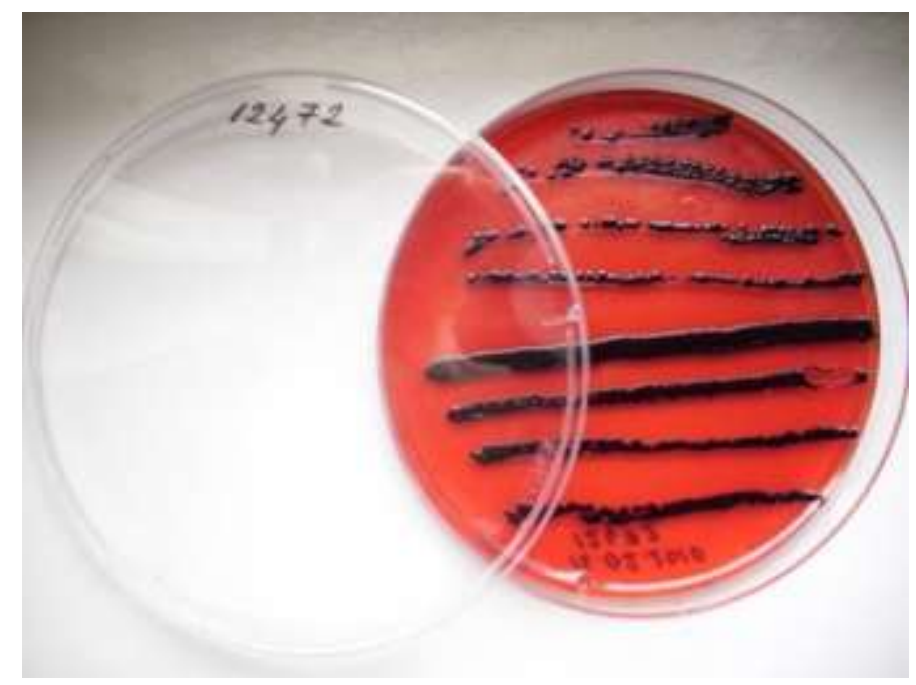

Şekil 1. C.violaceum 12472 orijinal suş 


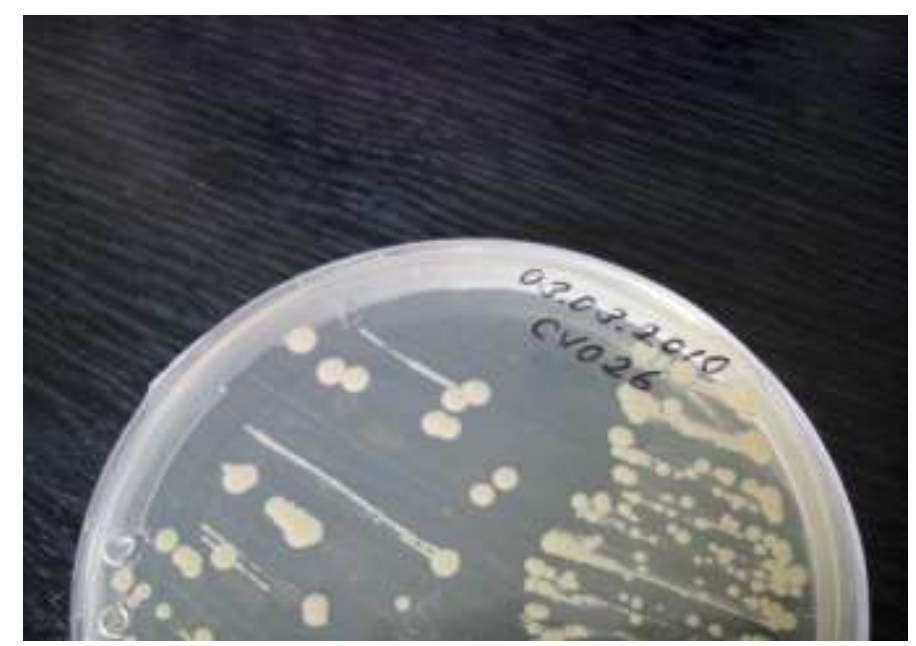

Şekil 2. C. violaceum CV026 mutant suş

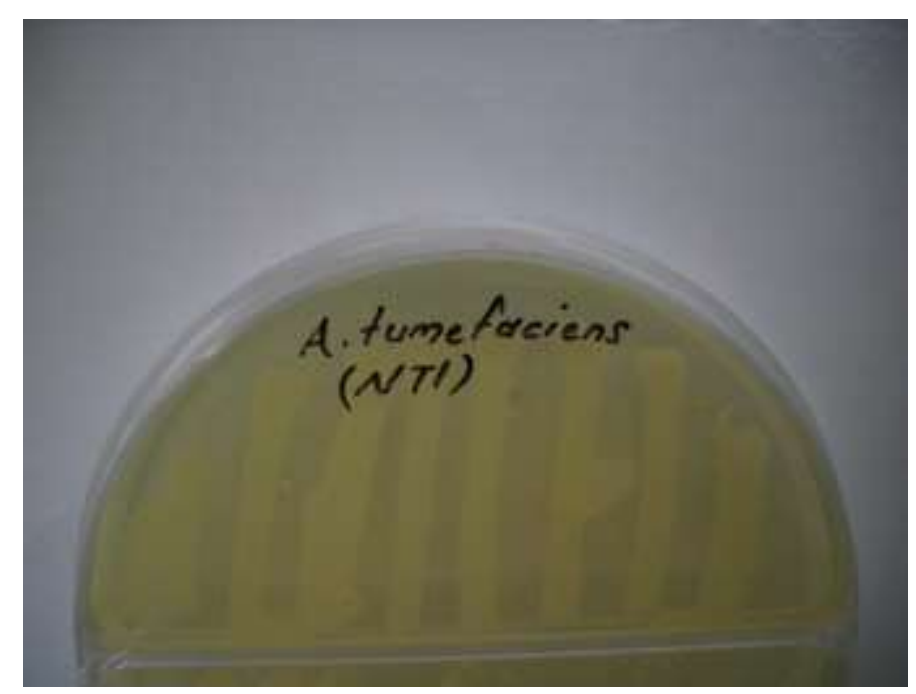

Şekil 3. A. tumefaciens NT1 mutant suş

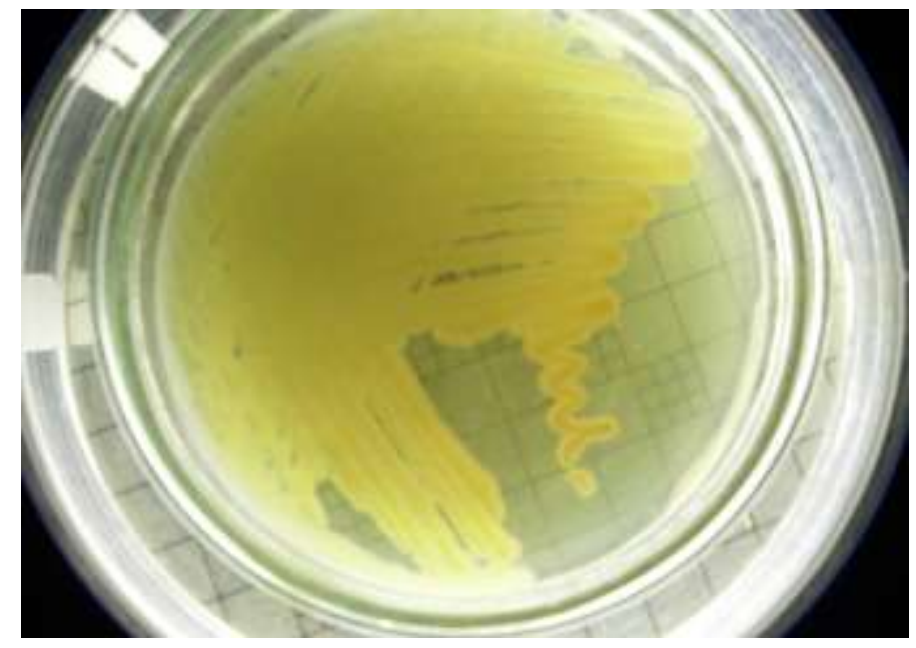

Şekil 4. P.aeruginosa PAO1 


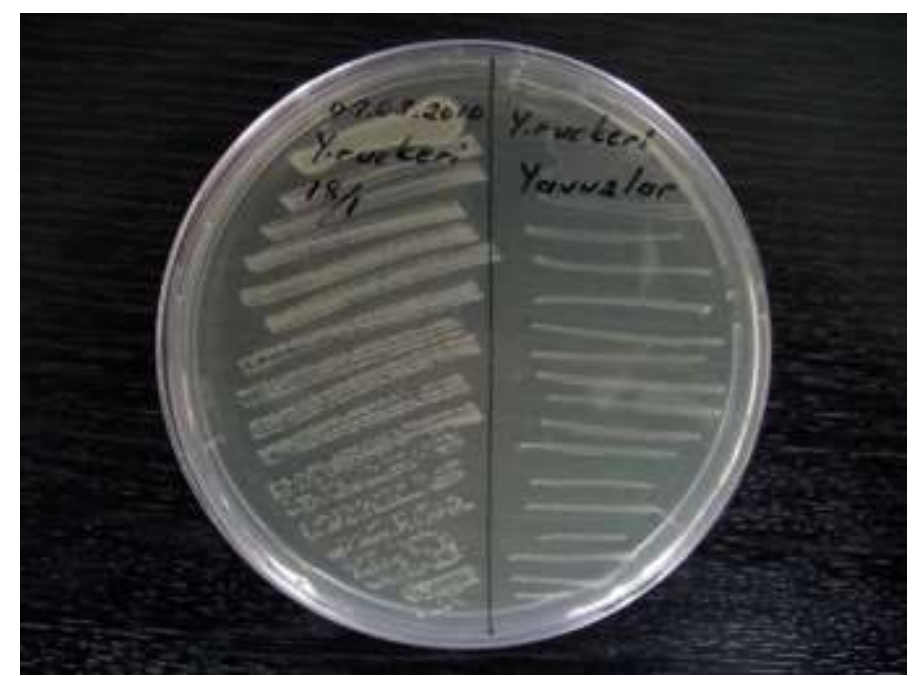

Şekil 5. Y. ruckeri

Mikrobiyolojik monitör sistemleriyleY. ruckeri'de $N$-acyl Homoserin Lakton (AHL) Sinyal Moleküllerinin Tespiti

Sinyal molükülünün varlığı fenotipik olarak araştırılmıştır. $Y$. ruckeri suşların koloni renk değişimiyle BHL ve OdDHL moleküllerini üretip üretmediği takip edilmiştir (Şekil 6). SonuçtaY. ruckeri suşlarının $C$. violaceum $\mathrm{CV} 026$ suşu aracılığıylakrem renkten mor renge dönüşmesiyle $\mathrm{BHL}$ sinyal molekülünü (Şekil 7) ürettĭgi, A. tumefaciens NT1 suşu aracılığıyla dakrem renkten yeşil renge dönüşmesiyle OdDHL sinyal molekülünü ürettiği tespit edilmiştir (Şekil 8).

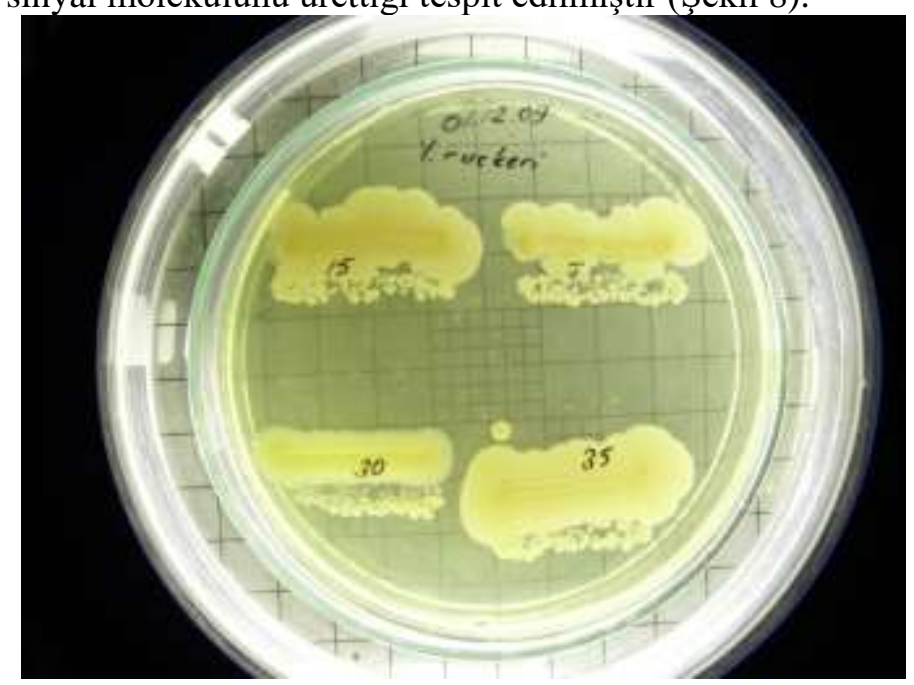

Şekil 6. Üreyen Y. ruckeri suşların koloni renk değişimiyle BHL ve OdDHL molekülleri üretiminin takibi

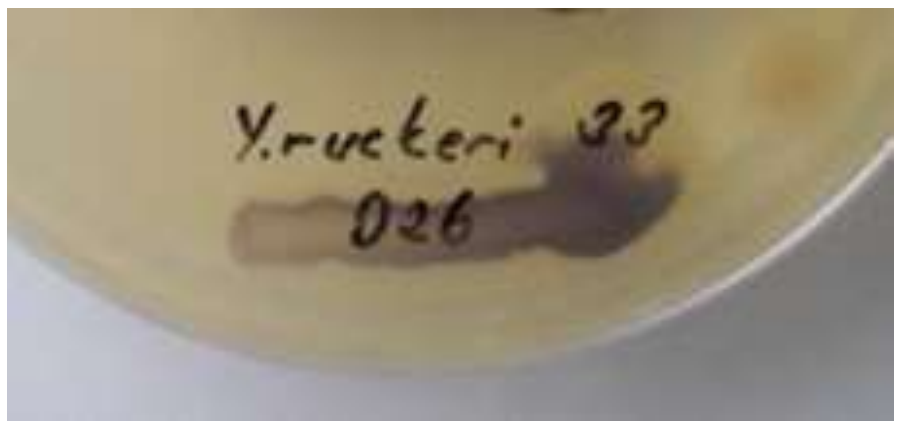

Şekil 7. C. violaceum CV026 aracılığıyla Y. Ruckeri suşlarında BHL sinyal moleküllerinin üretimi 


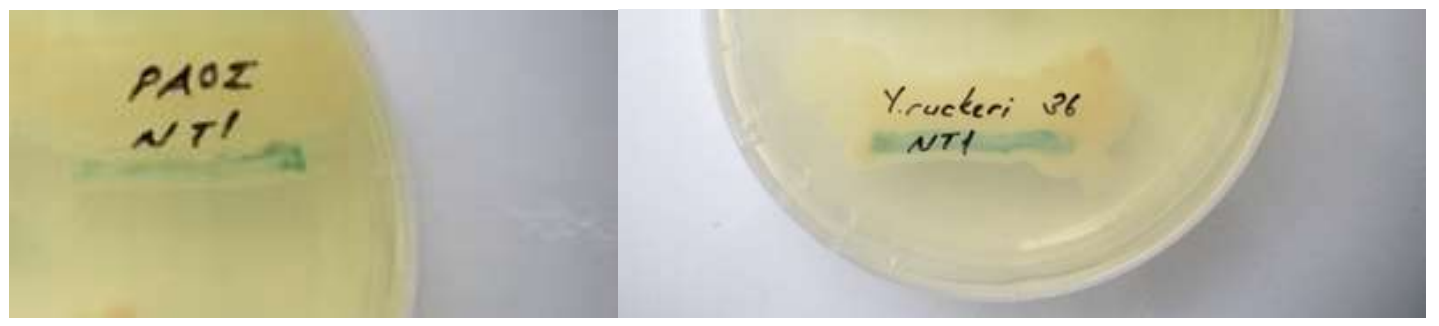

Şekil8. A. tumefaciens NT1 aracılı̆̆ıla $Y$. ruckeri ve $P$. aeruginosa (+kontrol) suşlarında OdDHL sinyal moleküllerinin üretimi

\section{BHL ve OdDHL Sinyal Moleküllerine Bağımlı Virülens Faktörlerinin Araştrılması}

Deneysel çalışmalarla balık patojeni ramnolipid, elastaz, proteaz, amilaz, hemoliz üretimi gibi çevreyi algılama sistemi tarafından kontrol edilen virülens faktörlerinin varlığı veya yokluğu bakımından test edilmiştir. Araştırma sırasında kullanılan suşlar ve Y. ruckeri suşlarının tamamının testlere verdiği cevaplar gösterilmiştir(Tablo 1).

\section{Y. ruckeri'de Elastaz, Ramnolipid, Proteaz, Amilaz ve Hemoliz Bulguları}

$P$. aeruginosa'nın ürettiği bilinen ve balık patojenine uyarlanan elastaz testinde $Y$. ruckeri'nin tüm suşlarında optik yoğunluğuna bakılarak elastaz üretimi azda olsa tespit edilmiştir (Şekil 9). Sonuçlar incelendiğinde $Y$. ruckeri'nin tüm suşlarında agar testlerinde ramnolipid, proteaz, amilaz ve hemoliz üretimi tespit edilmemiştir.

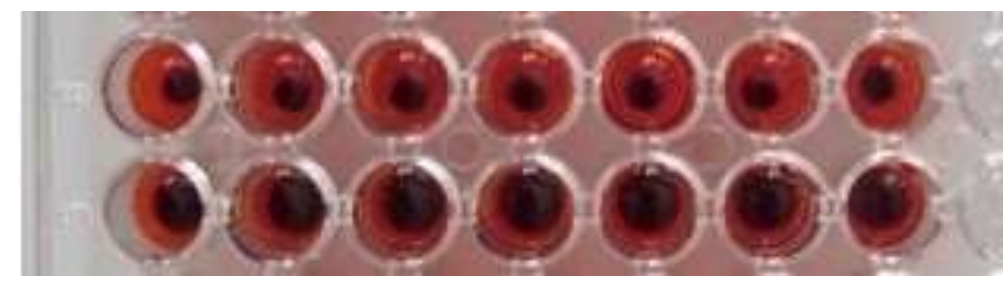

Şekil 9. Y. ruckeri suşlarında elastaz virülens faktörünün varlığı

Tablo 1. Araştırma sırasında kullanılan suşlar veY. ruckeri suşlarının tamamının testlere verdiği cevaplar

\begin{tabular}{|c|c|c|c|c|c|c|c|}
\hline Suş Adı & Özellik & $\begin{array}{c}\text { Çevreyi } \\
\text { AlgılamaSinyal } \\
\text { Molekülü Tipi }\end{array}$ & Elastaz & Ramnolipid & Proteaz & Amilaz & Hemoliz \\
\hline P. aeruginosa* & $\begin{array}{l}\text { PAO1 PT5 } \\
\text { orijinal tip }\end{array}$ & + Kontrol & & & & & \\
\hline C.violaceum* & CV026 & Biyosensör Suş & & & & & \\
\hline A. tumefaciens* & NT1 & Biyosensör Suş & & & & & \\
\hline Y. ruckeri & Yavuzlar & BHL ve OdDHL & + & - & - & - & - \\
\hline Y. ruckeri & 15 & BHL ve OdDHL & + & - & - & - & - \\
\hline Y. ruckeri & 17 & BHL ve OdDHL & + & - & - & - & - \\
\hline Y. ruckeri & $18 / 1$ & BHL ve OdDHL & + & - & - & - & - \\
\hline Y. ruckeri & $18 / 2$ & BHL ve OdDHL & + & - & - & - & - \\
\hline Y. ruckeri & 28 & BHL ve OdDHL & + & - & - & - & - \\
\hline Y. ruckeri & $29 / 1$ & BHL ve OdDHL & + & - & - & - & - \\
\hline Y. ruckeri & 30 & BHL ve OdDHL & + & - & - & - & - \\
\hline Y. ruckeri & 33 & BHL ve OdDHL & + & - & - & - & - \\
\hline Y. ruckeri & 34 & BHL ve OdDHL & + & - & - & - & - \\
\hline Y. ruckeri & 35 & BHL ve OdDHL & + & - & - & - & - \\
\hline Y. ruckeri & 36 & BHL ve OdDHL & + & - & - & - & - \\
\hline
\end{tabular}

\section{TARTIŞMA ve SONUÇ}

Bakteriler istedikleri çoğunluğa ulaştıklarını anladıkları anda virülens faktörleriyle konak üzerindeki etkisini gösterirler (Watve vd., 2019). En ilkel canlılardan biri olarak bilinen bakterilerin sistemleşmiş milyarlarca hücreden oluşan balıkların dokularında hastalık oluşturarak yetiştiricilik 
ünitelerinde nasıl büyük ölçüde kayıplara sebep olduğu sorusunun cevaplarından birisi, çevreyi algılamadır. Su ürünleri yetiştiriciliğinde hastalık kayıplarının azaltılması için kullanılan profilaktif yöntemlere ek olarak aternatif yeni metotlara gereksinim vardır. Çevreyi algılama sistemini durdurma bunlardan bir tanesidir (Defoirdt vd., 2004).

Temprano vd. (2001) tarafından beyaz mutant $C$. violaceum CV026 ile karş1lıklı çapraz olarak inoküle edilen $Y$. ruckeri'nin çevreyialgılama sistemine sahip olduğu saptanılmıştır. Beyaz mutant $C$. violaceum CV026 biyosensör suşu kullanılarak yapılan bu çalışmada da çapraz ekimde Y. ruckeri'nin tüm suşlarında çevreyi algılama sinyal molekülleri bulunmuştur.

Kastbjergvd. (2007)'e göreN-(3-oxooctanoyl)-L-homoserin lakton (3-oxo-C8-HSL), $N$-(3oxoheptanoyl)-L-homoserin lakton (3-oxo-C7-HSL) ve $N$-(3-oxononanoyl)-L-homoserin lakton (3oxo-C9-HSL) üretmiştir. Benzer şekilde Temperano vd. (2001)'e göre Y. ruckeri'de sinyal molekülleri vardır. Söz konusu araştırmamız da $Y$. ruckeri suşlarının tamamınınmor renkli koloni oluşturmasıyla BHL ve yeşil renkli koloni oluşturmasıyla OdDHL sinyal moleküllerini ürettiği ispatlanmıştır.

Y. ruckeri'nin ekstraselüler ürünlerinin (ECP), lipazlar, proteazlar ve hemolizinler de dâhil olmak üzere, balıklara enjekte edildiğinde, ağızda ve bağırsaktaki kanamalar gibi bazı karakteristik ERM (Enteric redmouth) bulguları üretirler. $\mathrm{Bu}$ nedenle, bu ECP'lerin $Y$. ruckeri enfeksiyonunun patogenezinde rol oynadığı görülmektedir (Tobback, 2009).

Ulusoy (2007) araştırmasında $P$. aeruginosa PAO1 suşunda elastazınolduğunu bulmuştur. Ulusoy (2007)'dan modifiye edilerek balık patojenine uyarlanan teste $P$. aeruginosa PAO1 suşuna özgü virülens faktörü olan elastaz aktivitesine $Y$. ruckeri suşlarının tamamında rastlanmıştır.

Kumar vd. (2015)'ne göre $Y$. ruckeri'nin birçok virülans mekanizması tanımlanmıştır. Bazı hücre dışı ürünlerin (ECP), konakçılarına tekrar enjekte edildiklerinde hastalığın hemorajik formu ile ilişkili klinik bulguları çoğalttığı gösterilmiştir. Bu ECP'nin virülensi tetiklediği bilinmektedir. Azokazin proteaz, sitolitik ve hemolitik aktiviteleri düzenleyenhemolizin YhlA ile geniş bir hedefe sahip olan ve özellikle fibronektin, aktin ve miyozin parçalanmasında etkili olan $47 \mathrm{kDa}$ metalloproteaz Yrplbuna örnektir. Ancak araştırmamızda ECP üzerinde bu denli etkili olan proteaz, hemoliz ve amilaz sonuçları çalışılan tüm suşlarda negatiftir.

Ulusoy (2007) araştırmasında $P$. aeruginosa PAO1 suşundaramnolipidin olduğunu bulmuştur. Ulusoy (2007)'dan modifiye edilerek balık patojenine uyarlanan teste $P$. aeruginosa PAO1 suşuna özgü virülens faktörü olan ramnolipid aktivitesine $Y$. ruckeri suşlarının tamamında rastlanmamış ve sonuçlar araştırıcıdan farklılık göstermiştir.

Ulusoy (2007) tarafından çevreyi algılama sisteminde rol alan BHL sinyal molekülü aracıllğıyla balık patojenleriA. hydrophila'nın Ahyl/AhyR regülatör proteinleriyle ekzoproteaz üretimini gerçekleştirdiği, A. salmonicida'nın ise AsaI/AsaR regülatör proteinleriyle hücredışı proteazüretimini gerçekleştirdiği bildirilmiştir. Fakat çalışılan $Y$. ruckeri suşlarının tamamında proteaz negatif belirlenmiştir.

Romalde ve Toranzo (1993)'a göre patolojik bir aktivite olan amilaz Y. ruckeri suşlarının tamamında pozitifken bu araştırmada negatiftir.

Fernández vd. (2007)'e göre $Y$. ruckeri'nin patojenitesinde YhlA olarak adlandırılan hemolizin/sitolizin'in önemli bir rol oynadığını vehemolizin YhlA, eritrositlerin yanı sıra kültür balığının doku hücrelerini de eritebilmişlerdir. Aynı zamanda YhlA'nın üretimi için iki genin gerekli olduğunu bildirmişlerdir. Ancak çalışılan Y. ruckeri'nin busuşlarının tamamında hemoliz aktivitesi görülmemiştir.

Patojenitenin oluşumunda, bakteriyel çevreyi algılama karmaşık olduğu için (Boyen vd., 2009), bakteriyel patojenler tarafından üretilen sinyal molekülleri, enfeksiyonların teşhis ve tedaviedilmelerinde yol göstericilerdir (Kumari vd., 2008; Boyen vd., 2009). Spor oluşturma, konjugasyon, biyolüminesans, biyofilm oluşturma, antibiyotik üretimi ve bakteriyosin üretimi gibi türe özgü pek çok davranış çevreyi algılama mekanizması ile kontrol edilmektedir. Çevreyi algılamanın anlaşılması ile yeni dönem probiyotikler olarak tanımlanan metabiyotiklerin tasarlanmasında yarar sağlayacağı düşünülmektedir (Boyen vd., 2009).

İletişim, tüm canlılarda olduğu gibi bakterilerde de çok etkin bir olgudur. İletişimin gücüyle mikroorganizma virülent olmakta, hastalık oluşturmayla balık üzerinde ölümcül olabilmektedir. Elde edilen veriler ışı̆̆ında bakteri hücreleri arasındaki iletişimin engellenmesiyle (Quorum Quenching, QQ) antibakteriyel etki elde etme çalışmaları gelecek için umut vaadeden bir alan olarak görülmektedir. $\mathrm{Bu}$ esasla çevreyi algılamanın durdurulmasıyla enfeksiyon gücünün azaltılması su 
ürünleri yetiştiriciliğinde hastalıktan korunmaarayışlarında alternatif bir metottur. Aynı zamanda quorum quenching modasıyla çevreyi algılama sinyal moleküllerinin tespit edilmesi, bu moleküllerin oluşumunun inhibitörler, mimikler, enzimler aracılığıyla durdurulması hastalıkta erken teşhis kavramını gündeme getirmekte ve bu durumunda balık hastalıkları profilaksisinde önemli olması hedeflenmektedir.

Y. ruckeri suşlarının tamamının çevreyi algılama sistemini kullandığı ve bu sistemin yönetimindeki virülens faktörlerinden elastazı ürettiği bulunmuştur. Araştırmada BHL ve OdDHL sinyal molekülleri aracılığıyla $Y$. ruckeri'nin çevreyi algılama sistemini kullandığının ispatıyla insan patojenine özgü elastaz ve ramnolipid gibi patolojik etkenlerden elastaza $Y$. ruckeri'de rastlanmasının araştırmaya orijinallik kattığını düşünmekteyiz. Bu araştırma makalesinin $Y$. ruckeri'de çevreyi algılama tespitiyle bir sonraki adım olarak bu patojenleilgili quorum quenchingçalışmalarına ve İn vivo çalışmalara yön göstereceği kanaatindeyiz.

Teşekkür: Çalışma, 1973-YL-09 No'lu Proje ile Süleyman Demirel Üniversitesi Bilimsel Araştırma Projeleri Koordinasyon Birimi tarafından maddi olarak desteklenmiş olan yüksek lisans tezinden özetlenmiştir.

\section{KAYNAKLAR}

Arda, M.(1997). Temel Mikrobiyoloji. Medisan Yayınevi, Medisan Yayın Serisi No:25, 490s, Ankara.

Asif, A., Iftikhara, A., Hamoodb, A., Colmer-Hamood, J.A., \& Qaisar, U. (2019). Isonitrile-functionalized tyrosine modulates swarming motility and quorum sensing in Pseudomonas aeruginosa. Microbial Pathogenesis, 127, 288-295.

Austin, B., \& Austin, D.A. (1999). Bacterial fish pathogens. Diseases in famed and wild fish. 3rd (Revised), Ellis Horwood Ltd., Chichester, UK, pp 457.

Austin, B., \&Austin, D.A. (1987). Bacterial Fish Pathogens: Disease in farmed and wild fish. First Edition, Ellis Horwood Ltd., Chichester, UK, pp 364.

Austın, B., Green, M.,\& Rodgers, J.C. (1982). Morphological diversity among strains of Yersinia ruckeri. Aquaculture, 27, 73-78.

Balta, F., Balta, Z.D., Özgümüş, O.B., \& Çağırgan, H. (2016).Doğu Karadeniz Bölgesi’ndeki Gökkuşağı Alabalığı (Oncorhynchus mykiss) Çiftliklerinde Yersinia ruckeri'nin Portörlük Yönünden Tetkiki ve Antimikrobiyal Direncin Tespiti. Journal of Anatolian Environmental \& Animal Sciences (Anadolu Çevre ve Hayvancılık Bilimleri Dergisi), 1(3), 72-76.

Baskın, H. (2005). Mikroorganizmanın Çevreye Uyumu ve Biyofilm: "Quorum Sensing" (Çoğunluğu Algılama). Klimik 2005 XII. Türk Klinik Mikrobiyoloji ve İnfeksiyon Hastalıkları Kongresi. Dokuz Eylül Üniversitesi Tıp Fakültesi Mikrobiyoloji ve Klinik Mikrobiyoloji Anabilim Dalı, İzmir, 9-10.

Boşgelmez-Tınaz, G.(2003). Quorum Sensing in Gram-Negative Bacteria. Turkish Journal of Biology, 27, 8593.

Boyen, F.,Eeckhaut, V., Van Immerseel, F., Pasmans, F., Ducatelle, R., \& Haesebrouck, F.(2009). Quorum sensing in veterinary pathogens: Mechanisms, clinical importance and future perspectives. Veterinary Microbiology, 135, 187-195.

Bruhn, J.B., Dalsgaard, I., Nielsen, K.F., Buchholtz, C., Larsen J.L., \& Gram L. (2005).Quorum sensing signal molecules (acylated homoserine lactones) in Gram-negativefish pathogenic bacteria. Diseases of Aquatic Organisms, 65, 43-52.

Davies, R.L., \& Frerichs, G.N. (1989). Morphological and biochemical differences among isolates of Yersinia ruckeri obtained from wide geographical areas. Journal of Fish Diseases, 12, 357-365.

Defoirdt, T., Boon, N., Bossier, P., \& Verstraete, W. (2004). Disruption of bacterial quorum sensing: an unexplored strategy to fight infections in aquaculture. Aquaculture, 240, 69-88.

Delshad, S.T.,Soltanian, S., Sharifiyazdi, H., \& Bossier, P. (2018). Effect of quorum quenching bacteria on growth, virulence factors and biofilm formation of Yersiniaruckeri in vitro and an in vivo evaluation of their probiotic effect in rainbow trout. Journal of Fish Diseases, 41(9), 1429-1438. doi: 10.1111/jfd.12840.

Donabedian, H. (2003). Quorum sensing and its relevance to infectious diseases. Journal of Infection 46, $207-$ 214.

Dong, Y., Zhang, X., Soo, H.L., Greenberg, P., \& Zhang, L. (2005). The two-component response regulator PprB modulates quorum-sensing signal production and global gene expression in $P$. aeruginosa. Molecular Microbiology, 56, 1287-1301. 
Farrand, S.K. (1998). Conjugation in Rhizobiaceae. In: The Rhizobiaceae, Molecular Biology of Model PlantAssociated Bacteria (Spaink, H.P., Kondorosi, A. and Hooykaas, P.J.J., Eds.), 199-233. Kluwer Academic, Dordrecht.

Fernández L., Prieto M., \& Guijarro J.A. (2007). The iron- and temperature-regulated haemolysin YhlA is a virulence factor of Yersinia ruckeri. Microbiology, 153, 483-489.

Frerichs, G.N. (1993). Isolation and identification of fish bacterial pathogens. In: Bacterial Diseases of Fish (ed. by V. Inglis, R.J. Roberts \& N.R. Bromage), 270-272. Blackwell Scientific Publications, Oxford.

Fugua, W.C., Winans, S.C., \& Greenberg, E.P. (1994).Quorum sensing in bacteria: the LuxR-LuxI family of cell density-responsive transcriptional regulators. Journal of Bacteriology, 176(2), 269-275.

Fuhrmann, H., Böhm. H.K., \& Schlotfeldt, J.H. (1983). An outbreak of enteric redmouth disease in West Germany. Journal of Fish Diseases, 6, 309-311.

Furones, M.D. Rodgers, C.J., \& Munn, C.B. (1993). Yersinia ruckeri, the causal agent of enteric redmouth disease (ERM) in fish. Annual Review of Fish Diseases, 3, 105-125.

Gawande, B.N., \& Patkar, A.Y.(2001). Purification and properties of a novel raw starchdegrading cyclodextrin glycosyltransferase from Klebsiella pneumoniae AS-22. Enzyme and Microbial Technology, 22,735-743.

Hamood, A.N., Griswold, J., \& Colmer, J.(1996). Characterization of elastase-deficientclinical isolates of $P$. aeruginosa. Infection and Immunity, 64, 3154-3160.

Hellingwerf, K.J. (2005). Bacterial observations: a rudimentary from of intelligence? Trends in Microbiology, 13(4), 152-158.

Jangid, K., Kong, R., Patole, M.S., \& Shouche, Y.S.(2007). luxRI homologs are universally present in the genus Aeromonas. BMC Microbiology, 7, 93, 1-11.

Kastbjerg, V.G., Nielsen, K.F., Dalsgaard I., Rasch M., Bruhn J.B., Givskov M.\& Gram L.(2007).Profiling acylated homoserine lactones in Yersinia ruckeri and influence of exogenous acyl homoserine lactones and known quorum-sensing inhibitors on protease production. Journal of Applied Microbiology, 102(2), 363-74.

Kleerebezem, M., Quadri, L.E., Kuipers, O.P., \& de Vos, V.M. (1997). Quorum sensing by peptide pheromones and two-component signal-transduction systems in gram-positive bacteria. Molecular Microbiology, 24, 895-904.

Kumar, G.,Menanteau-Ledouble, S., Saleh, M., \& El-Matbouli, M. (2015). Yersinia ruckeri, the causative agent of enteric redmouth disease in fish. Veterinary Research, 46, 103, doi: 10.1186/s13567-015-0238-4.

Kumari, A., Pasini, P., \& Daunert, S.(2008). Detection of bacterial quorum sensing $N$-acyl homoserine lactones in clinical samples. Analytical and BioanalyticalChemistry,391, 1619-1627.

McClean, K.H., Winson, M.K., Fish, L., Taylor, A., Chhabra, S.R., Camara, M., Daykin, M., Lamb, J.H., Swift, S., Bycroft, B.W., Stewart, G.S.A.B., \& Williams, P.(1997). Quorum sensing and Chromobacterium violeceum: exploitation of violacein production for the detection of $N$-acylhomoserine lactones. Microbiology, 143, 3703-3711.

Moghaddam, M.M., Khodi, S., \& Mirhosseini, A. (2014) Quorum Sensing in Bacteria and a Glance on Pseudomonas aeruginosa. Clinical Microbiology, 3(4),1-10.

Ohman, D.E., Cryz, S.J., \& Iglewski, B.H. (1980). Isolation and characterization of a P. aeruginosa PAO mutant that produces altered elastase. Journal of Bacteriology, 142, 836-842.

Ohtani, M. Villumsen, K.R.,Strøm, H.K., Lauritsen, A.H., Aalbæk, B., Dalsgaard,I., Nowak, B., Raida, M.K., \& Bojesen, A.M. (2019). Effects of fish size and route of infection on virulence of a Danish Yersinia ruckeri $\mathrm{O} 1$ biotype 2 strain in rainbow trout (Oncorhynchus mykiss). Aquaculture, 503, 519-526, doi: 10.1016/j.aquaculture.2019.01.041.

Onwosi, C.O., \& Odibo, F.J.C. (2012). Effects of carbon and nitrogen sources on rhamnolipid biosurfactant production by Pseudomonas nitroreducens isolated from soil. World Journal of Microbiology and Biotechnology, 28, 937-942, doi: 10.1007/s11274-011-0891-3.

Ormsby, M.J.,Grahame, E., Burchmore, R., \& Davies, R.L. (2019). Comparative bioinformatic and proteomic approaches to evaluate the outer membrane proteome of the fish pathogen Yersinia ruckeri.Journal of proteomics, 199, 135-147, doi:10.1016/j.jprot.2019.02.014

Petrie, J., Bronu D.W., \& Hastings, T.S. (1996). İsolation of Yersinia ruckeri from wild Atlantik salmon, Salmo salar L., in Northern Finland. Journal of Fish Diseases, 14, 137-140.

Polaina, J., \& MacCabe, A.P.(2007). Industrial Enzymes: Structure. Function andApplications, Springer, The Netherlands.

Raffa, R.B., Iannuzzo, J.R., Levine, D.R., Saeid, K.K., Schwartz, R.C., Sucic, N.T.,Terleckyj, O.D., \& Young, J.M.(2005). Bacterial Communication ("QuorumSensing") via Ligands and Receptors: A Novel Pharmacologic Target for theDesign of Antibiotic Drugs. The Journal of Pharmacology and Experimental Therapeutics, 312(2), 417-423. 
Rigos, G., \& Stevenson, R. (2001). The effect of antibiotic treatment on the establishment of persistent infection with Yersinia ruckeri serovar II in rainbow trout Oncorhynchus mykiss (Walbaum). Aquaculture, 9, 247253.

Rodgers, J.C. (1992). Development of a selective-differential medium for the isolation of Yersinia ruckeri and its application in epidomilogical studies. Journal of Fish Diseases, 15, 243-254.

Romalde, J.L., \&Toranzo, A.E. (1993) Pathological activities of Yersinia ruckeri, the Enteric Redmouth (ERM) bacterium. FEMS Microbiology Letters, Federation of European Microbiological Societies, 112, 291300.

Rumbaugh, K.P., Griswold, J.A., Iglewski, B.H., \& Hamood, A.N. (1999). Contributionof quorum sensing to the virulence of $P$. aeruginosa in burn woundinfections. Infection and Immunity, 67, 5854-5862.

Sarabhai, S., Kaur, A., Capalash, N., \& Sharma, P. (2016). Quorum sensing in Pseudomonas aeruginosa: mechanism and regulation of virulence. In Pseudomonas: Molecular and Applied Biology (pp. 231-256).

Salyers, A.A., \& Whitt, D.D. (1994). Bacterial pathogenesis: a molecular approach. 1st ed. Washington, D.C: ASM Press, 260-268, USA.

Secades, P., \& Guijarro,J.A. (1999). Purification and characterization of an extracellular protease from the fish pathogen Yersinia ruckeri and effect of culture conditions on production. Applied and Environmental Microbiology, 65(9), 3969-3975.

Sequences,(2008). Bakteri hücreleri arasında haberleşme (Cell-to-cellcommunication: quorum sensing). http://www.genotyping.wordpress.com.http://genotyping.wordpress.com/2008/05/12/bakteri-hucreleriarasindahaberlesme- cell-to-cell-communication-quorum-sensing/. Erişim Tarihi: 28.03.2010.

Sharma, A., Sahgal, M., \& Johri, B.N.(2003). Microbial communication in the rhizosphere: Operation of quorum sensing. Current Science, 85(8), 1164-1172.

Siegmund, I., \& Wagner, F. (1991). New methods for detecting rhamnolipids excretedby Pseudomonas species during growth in mineral agar. BioTechniques, 5, 265-268.

Swift, S., Lynch, M.J., Fish, L., Kirke, D.F., Tomas, J.M., Stewart, G.S.A.B., \& Williams, P. (1999). Quorum Sensing-Dependent Regulation and Blockade of Exoprotease Production in Aeromonas hydrophila. Infection and Immunity, 67(10), 5192-5199.

Swift, S., Karlyshev, A.V., Fish, L., Durant, E. L., Winson, M.K., Chhabra, S.R.,Williams, P., Macintyre, S., \& Stewart, G.S.A.B.(1997). Quorum Sensing in Aeromonas hydrophila and Aeromonas salmonicida: Identification of theLuxRI Homologs AhyRI and AsaRI and Their Cognate $N$-AcylhomoserineLactone Signal Molecules. Journal of Bacteriology, 179(17), 5271-5281.

Swift, S., Throup, J.P., Williams, P., Salmond, G.P., \& Stewart, G.S.(1994). Quorum sensing: a populationdensity component in the determination of bacterial phenotype. Trends in Biochemical Science, 21, 214219.

Temprano, A., Yugueros, J., Hernanz, C., Sánchez, M., Berzal, B., Luengo, J.M., \& Naharro, G.(2001). Rapid identification of Yersinia ruckeri by PCR amplification of yruI-yruR quorum sensing. Journal of Fish Diseases, 24(5), 253-261.

Tkachenko, H., Buyun, L., Terech-Majewska, E., Honcharenko, V., Prokopiv, A., \& Osadowski, Z. (2019). Preliminary in vitro screening of the antibacterial activity of leaf extracts from various Ficus species (Moraceae) against Yersinia ruckeri Fisheries \& Aquatic Life, 27, 15-26, Archives of Polish Fisheries, doi:10.2478/aopf-2019-0002.

Tobback, E.(2009). Early pathogenesis of Yersinia ruckeri infections in rainbow trout (Oncorhynchus mykiss, Walbaum). Thesis submitted in fulfilment of the requirements for the degree of Doctor in Veterinary Sciences (PhD), Faculty of Veterinary Medicine, Ghent University.

Turus, N.(2011). Alkali Soğukta Aktif Proteaz Üreticisi Bacillus sp. Suşlarının İzolasyonu, Enzim Üretimi, Karakterizasyonu ve Enzimin Biyoteknolojik Kullanım Olanakları Çukurova Üniversitesii, Fen Bilimleri Enstitüsü, Biyoteknoloji Anabilim Dalı, Yüksek Lisans Tezi, Adana, 92s.

Ulusoy, S. (2007). Yoğun Bakım Ünitelerinden İzole Edilen Pseudomonas aeruginosa Suşlarında $N$-Açil Homoserin Lakton Üretiminin Araştırılması. Süleyman Demirel Üniversitesi, Fen Bilimleri Enstitüsü, Doktora Tezi, 100s, Isparta.

Watve, S., Barrasso, K., Jung, S. A., Davis, K. J., Hawver, L. A., ... \& Perez, L. J. (2019). Ethanolamine regulates CqsR quorum-sensing signaling in Vibrio cholerae. bioRxiv, 589390. Williams, P. (2007). Quorum sensing, communication and cross-kingdom signallingin the bacterial world. Microbiology, 153, 3923-3938.

Yamamoto, K., Zhang, Z.Z., \& Kobayashi, S.(2000). Cycloamylose (cyclodextrin)glucanotransferase degrades intact granules of potato raw starch. Journal of Agricultural andFood Chemistry, 48, 962-966.

Ye, J., Ma, Y., Liu, Q., Zhao, D.L., Wang, Q.Y., \& Zhang, Y.X.(2008). Regulation ofVibrio alginolyticus virulence by the LuxS quorum-sensing system. Journalof Fish Diseases, 31, 161-169. 
Zhu, H., Bandara, R., Conibear, T.C.R., Thuruthyil, S.J., Rice, S.A., Kjelleberg, S.,Givskov, M., \& Willcox, M.D.P.(2004). P. aeruginosa with LasI quorum sensing deficiency during corneal infection. Investigative Ophthalmology and Visual Science, 45,1897-1903. 